\title{
O ENSINO DO DESENHO E ILUSTRAÇÃO DE MODA NA PRÁTICA DA EXTENSÃO
}

\section{The teaching of fashion drawing and illustration in the practice of extension}

\author{
Aderlange Sousa Araújo \\ Estilismo e Moda, professora \\ de vestuário, Instituto \\ Federal do Piauí, Piripiri-PI, \\ Brasil \\ Aderlange.sousa@ifpi.edu.br
}

\section{RESUMO}

0 desenho é de grande importância para o profissional de moda, especialmente aquele que desenvolve produtos. Entretanto, a realização de desenhos profissionais requer o domínio de técnicas que facilitem o entendimento da peça criada. Objetivos do curso de extensão são ensinar as técnicas tradicionais de desenho e ilustração, e também exercitar a capacidade imaginativa, de abstração e memória visual. A metodologia adotada no curso foi dividida em três etapas, no qual contou com aulas teóricas -práticas sobre desenhos e ilustração de moda. Os resultados obtidos na primeira etapa foram feitos diagnósticos, nos quais apontaram erros de observação do desenho (50\%), criação do traço (75\%), sombreado (90\%), erros no formato do corpo (75\%) e desproporção da figura humana (100\%). Na segunda etapa os resultados obtidos foram melhoria no traço, no sombreado e proporção exata do corpo humano, obedecendo a grade humana de 8 cabeças e meias. Na última etapa foram atingidos resultados significativos acerca da manipulação das técnicas de aplicação de cores, trabalhando o sombreado, proporção e diferentes métodos de ilustração. Com isso, conclui-se que os discentes que participaram de todas as etapas do curso obtiveram melhores desempenhos e desenhos profissionais, que no futuro facilitará a ingressão no mercado de trabalho.

Palavras-chave: pontilhismo, técnicas de desenho, figura humana, cânone.

\section{ABSTRACT}

The design is of great importance for the fashion professional, especially the one who develops products. However, the realization of professional drawings requires mastery of techniques that facilitate the understanding of the piece created. Objectives of the extension course are to teach the traditional techniques of drawing and illustration, and also to exercise the imaginative capacity, of abstraction and visual memory. The methodology adopted in the course was divided into three stages, in which theoretical classes - practical on drawings and illustration of fashion. The results obtained in the first stage were diagnosed, in which errors of the design (50\%), creation of the trait $(75 \%)$, shading (90\%), errors in body shape (75\%) and disproportion of the figure $(100 \%)$. In the second stage the results obtained were improvement in the trace, in the shading and exact proportion of the human body, obeying the human grid of 8 heads and socks. In the last step, significant results were obtained on the manipulation of the techniques of color application, working the shading, proportion and different methods of illustration. With this, it is concluded that the students who participated in all the stages of the course obtained better performances and professional designs, that in the future will facilitate the entry into the job market.

Keywords: pointillism, techniques of drawing, human figure, canon 


\section{INTRODUÇÃO}

A produção do vestuário é uma atividade profissional técnica, criativa e lucrativa, onde se insere no desenvolvimento econômico de uma região. A confecção de uma peça de roupa vai além de cortes e costura. É necessário, primeiramente, idealizá-la através do desenho, seja ele, ilustrativo ou técnico.

De acordo com Rodrigues (2003) o desenho não é apenas uma ornamentação, é um processo de criação visual que tem um propósito específico e, ao contrário de expressões pessoais de artistas como a pintura e a escultura, ele abrange necessidades práticas que poderão virar uma peça concreta. Para Riegelman (2006) o desenho é uma linguagem que possibilita a expressão e comunicação de ideias. Sendo assim, mediante o que foi exposto, podemos dizer que o desenho é de grande importância para o profissional de moda, pois auxilia na compreensão do processo criativo, estruturação e viabilidade do produto, é um vínculo entre aquilo que será confeccionado e a imagem mental que, a princípio, não está totalmente formada.

O designer de moda aprende ao longo do curso três tipos de desenho: o técnico, o de moda e a ilustração. Sendo o desenho técnico usado apenas como meio de comunicação entre quem projeta e quem fabrica. Os desenhos obedecem às normas técnicas de construção da ABNT (Associação Brasileira de Normas Técnicas) e são feitos a partir da observância detalhada das peças de roupas. Por outro lado, o desenho de moda e a ilustração apresentam uma linguagem de representação visual no qual transmitem ideias, sensações, informações e conceitos, elementos próprios deste universo, incorporando elementos culturais e sociais.

Neste sentido, a importância do desenho e da ilustração de moda para o profissional de design de moda está além de habilidades artísticas. É preciso conhecer as proporções do corpo humano e saber exatamente onde será a abertura, recortes e caimento de uma peça de roupa.

Riegelman (2000) recomenda o cânone de 9 cabeças, que mostra um desenho mais alongado. 0 exagero é habitual no desenho de moda e para conseguir uma figura mais estilizada recomenda-se alongar algumas partes do corpo e representar algum movimento, que é fundamental para apresentar diferentes poses da figura de moda. Ao conhecer e saber aplicar as técnicas de desenho e pintura, o desenhista de moda contribuirá de forma eficiente e eficaz na criação e desenvolvimento do produto de moda, como também poderá elaborar a ficha técnica, auxiliando na produção e possibilitando o apoio necessário ao crescimento empresarial. 
A fim de proporcionar conhecimento acerca do desenho e ilustração de moda este artigo tem como objetivo relatar a experiência no desenvolvimento de uma ação de extensão, na qual oferece um curso de desenho de moda e ilustração, cujo objetivo não só é ensinar as técnicas tradicionais já citadas neste artigo, mas também exercitar a capacidade imaginativa, de abstração e memória visual dos participantes.

\section{METODOLOGIA E EXPERIÊNCIA DE EXTENSÃO}

A ação de extensão através do curso "Desenho de Moda e Ilustração", foi desenvolvida no período de outubro de 2016 a janeiro de 2017, no laboratório de desenho do IFPI, campus Piripiri. Empregando nas aulas uma metodologia de observação, princípios do desenho e os conhecimentos de diferentes estilos de desenhos.

O curso de extensão foi ofertado gratuitamente e contou com o número de 20 pessoas, incluindo alunos do curso técnico integrado e concomitante/ subsequente, alunos do curso superior e pessoas da comunidade.

O laboratório de desenho do curso técnico em vestuário encontra-se estruturado com mesas próprias de desenho, revistas para pesquisas e materiais de consumo, como: lápis, borrachas, réguas, papéis sulfite e canson nos tamanhos A4 e A3, lápis de cor, hidrocor e canetas unipins número 0.1, 0.2 e 0.5 .

Os encontros aconteciam duas vezes por semana, com duração de 4 horas cada, dividos em dois momentos: teórico e prático. $\mathrm{Na}$ teoria foram abordados desde os diferentes tipos de desenhos, conceitos, histórico do surgimento do desenho e, por fim, apresentava-se produções de alguns ilustradores contemporâneos adeptos da técnica em questão. Em seguida, eram propostos exercícios práticos como objetivos daquela aula.

Este trabalho foi realizado em três etapas: a primeira constituiu-se do estudo bibliográfico para levantamento de dados e de conceitos, contextualização dos tipos de desenho e a diferença de cada um deles. $\mathrm{Na}$ segunda parte do curso os exercícios foram mais intensos, pois os discentes desenhavam a figura humana e seus membros com vistas diferentes. 0 método empregado para o desenho da figura humana foi o cânone de 8 cabeças e meia, obedecendo a técnica de proporção de Leonardo da Vinci.

Na última etapa do curso foram introduzidos o movimento do cânone, a figura estilizada de 9 cabeças e as cores nos desenhos de moda. Diferentes técnicas de pintura manuais como: pontilhismo (rosto feminino); pintura com lápis de cor; com hidrocor (canetinha) e a técnica de colagem usando lápis de cor para a pintura do croqui e diferentes materiais para a roupa finalizaram as ilustrações.

$\mathrm{Na}$ avaliação das etapas foram analisados os seguintes itens: traços, estilo do traço, proporções do desenho, manuseio dos materiais utilizados no desenho e evolução das técnicas executadas. 


\section{RESULTADOS}

No primeiro encontro do curso de extensão foi proposto aos participantes um exercício, no qual poderiam desenhar o que tinham vontade. 0 propósito da atividade era diagnosticar quais alunos tinham mais habilidades com desenho e como eram os traços e estilos de cada um deles. A figura 1 traz alguns desenhos que foram feitos sem o conhecimento prévio de nenhuma técnica.

Figura 1 - Desenho antes de técnicas empregadas no curso.

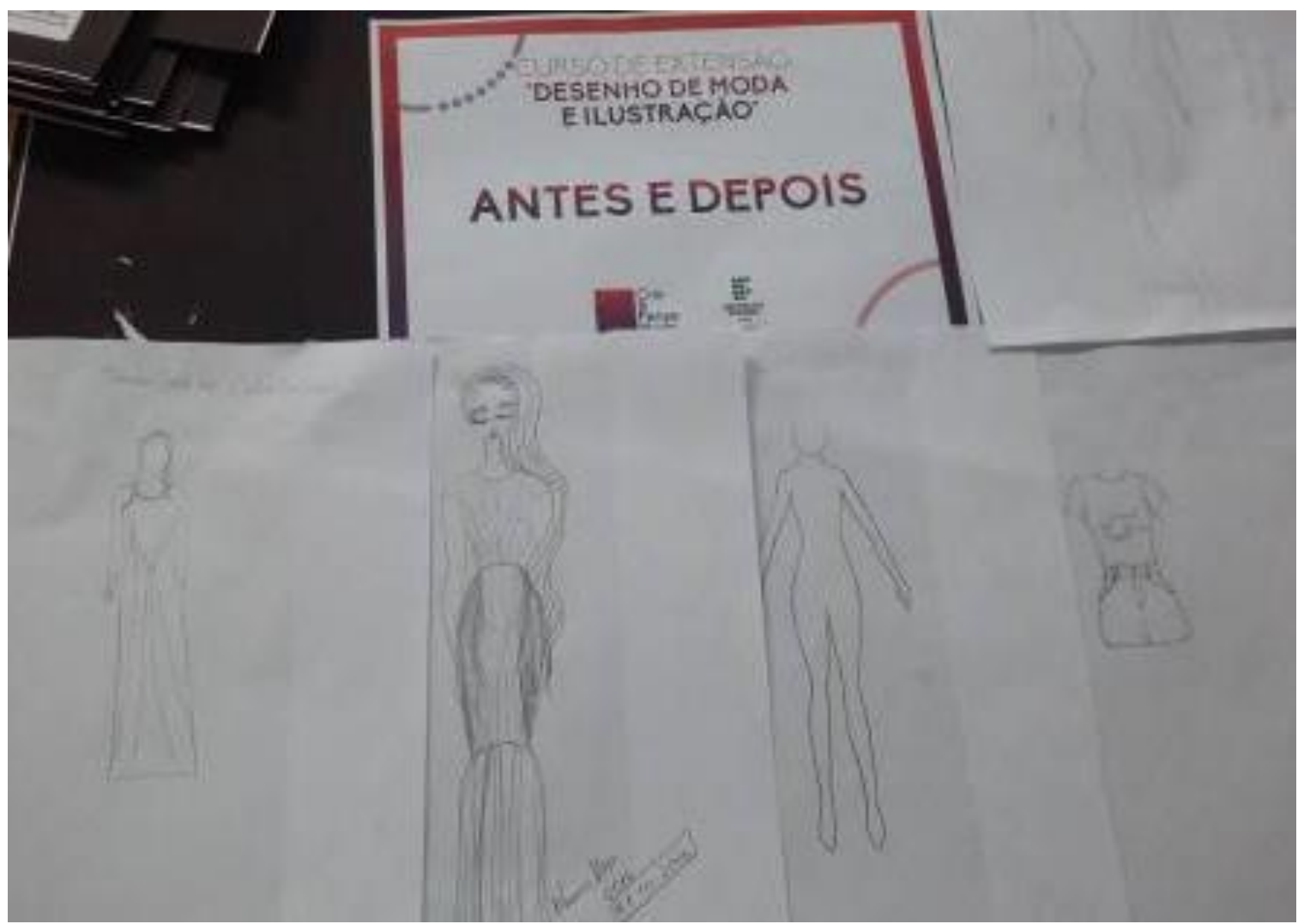

Fonte: IFPI campus Piripiri, 2016.

É visível que alguns tinham um bom traço, mas não tinham noção da proporção das figuras, outros participantes não sabiam desenhar o corpo humano e muitos esboçaram uma ideia do corpo humano, mas sem detalhe. Vale ressaltar que todos desenharam a figura feminina, mesmo não determinando que tipo de imagem deveriam ser desenhadas.

Passados essa diagnóstico inicial foram realizadas aulas teóricas sobre o que é o desenho, tipos de desenhos técnicos empregados na arquitetura, mecânica e na moda, onde utilizar os desenhos de moda e sua importância no 
mercado de trabalho. Logo em seguida os alunos desenvolveram atividades de desenho básico, entre eles: figuras geométricas, linhas e traços, etc. Nesta etapa foram diagnosticadas várias dificuldades dos discentes avaliados na pesquisa, como na observação do desenho, na criação dos traços, sombreamento, erros no formato do corpo e também na desproporção nas figuras (Tabela).

Tabela - Diagnósticos dos erros obtidos dos sujeitos participantes da primeira etapa do curso de extensão.

\begin{tabular}{lc}
\hline \multicolumn{1}{c}{ Fatores diagnosticados } & Erro (\%) \\
\hline Observação do desenho & 50 \\
Criação do Traço & 75 \\
Sombreado & 90 \\
Erros no formato do corpo & 75 \\
Desproporção nas figuras do corpo & 100 \\
humano & \\
\hline
\end{tabular}

De acordo com Roberto e Matos (2012), a justificativa para ocorrência destes erros nos desenhos é devida as atividades artísticas de desenho não serem uma prática comum a sociedade. Corroborando com os dados supracitados, Nunes et al. (2012) informam que o desenho e a pintura se fazem presentes desde os anos iniciais da criança, a princípio com mais intensidade na educação primária e vai enfraquecendo no ensino fundamental até quase extinção no ensino médio. 0 aluno perde o contato com o fazer artístico, até a fase adulta em que ele poderá optar ou não pelo universo artístico, seja continuando os estudos ou trabalhando na área.

Foram diagnosticados no estudo que alunos que tinham mais contato com o desenho obtiveram melhores resultados na observação e concentração no momento de desenhar, além de terem o traço mais firme e menos tremido. Já no sombreado tiveram um pouco de dificuldade, porém aprenderam rápido no segundo momento do curso.

No segundo momento foram realizadas práticas para corrigir os erros identificados na $1^{\underline{a}}$ etapa da pesquisa, empregando exercícios de sombreamento, proporções do corpo e partes individuais do corpo humano, como: olhos, nariz, boca, orelhas, cabeça, mãos e pés, todos representados com vistas de perfil, frente e $3 / 4$. De acordo com os exercícios da grade humana de 8 cabeças e meias, cada aluno realizou as atividades específicas para a correção e aprendizado. Na figura 2 mostra os resultados obtidos de dois alunos. $\mathrm{Na}$ figura $2 \mathrm{~A}$ apresentou melhor desempenho na técnica de sombreado, observação e proporção do corpo. Na figura 2B apresentou resultado inferior em relação a figura $2 \mathrm{~A}$. 
Figura 2 - Desenho de sombreamento e partes do corpo
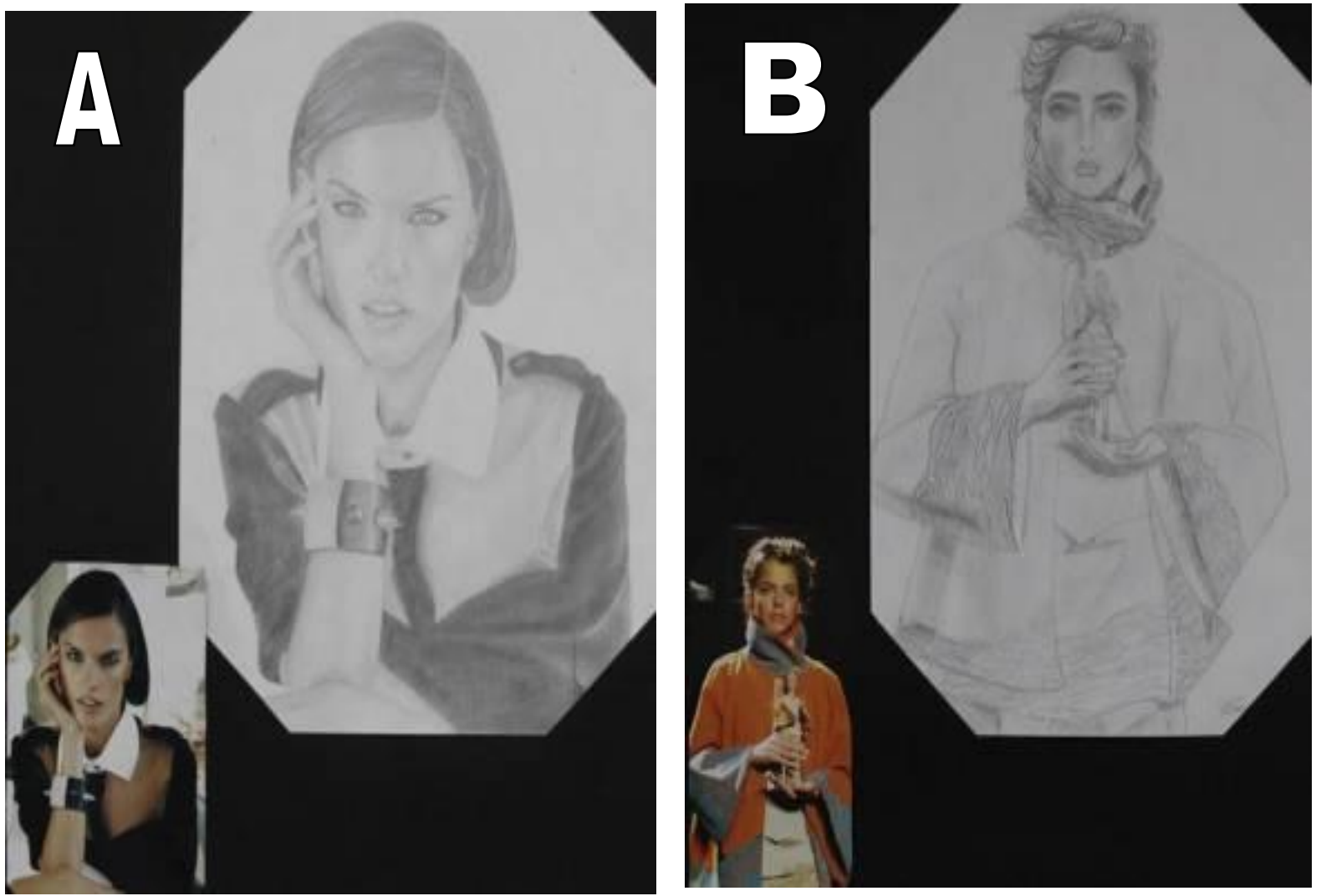

Fonte: IFPI campus Piripiri, 2016

$\mathrm{Na}$ figura 2A o discente empregou melhor o claro e escuro (jogo de sombras) dando mais realidade ao desenho, assim como seu desenho de observação teve maior detalhes e atenção em relação a figura 2B, que apresentou um bom desempenho no desenho de observação, porém, não trabalhou muito bem no sombreado, pois faltou mais domínio da técnica. Esse fato ocorreu pelo fato do aluno da figura 2B não frequentou as aulas do curso de extensão desde o início, e também por não ter muito contato com o desenho, apenas o desejo e vontade de aprender. Já o discente da figura 2A participou do curso desde o início, além de sempre ter contato com o desenho.

Segundo Rodrigues (2003), o bom desempenho do aluno da figura 2A é decorrente do processo lento no aprendizado do desenho, pois enquanto se aprende e as frustrações de início são superadas os resultados do trabalho vão surpreendendo positivamente, assim, conclui-se que quanto mais se desenha, mais prazer se tem e consequentemente melhor será o desenho.

$\mathrm{Na}$ terceira etapa foram usadas a técnica de pontilhismo com o uso da caneta nanquim representadas na figura 3 . Ambas as imagens mostram a evolução dos alunos ao realizarem essa atividade, sendo a prática mais 
demorada, precisando de maior atenção e paciência dos discentes que realizaram o trabalho.

Figura 3 - Desenho de pontilhismo.

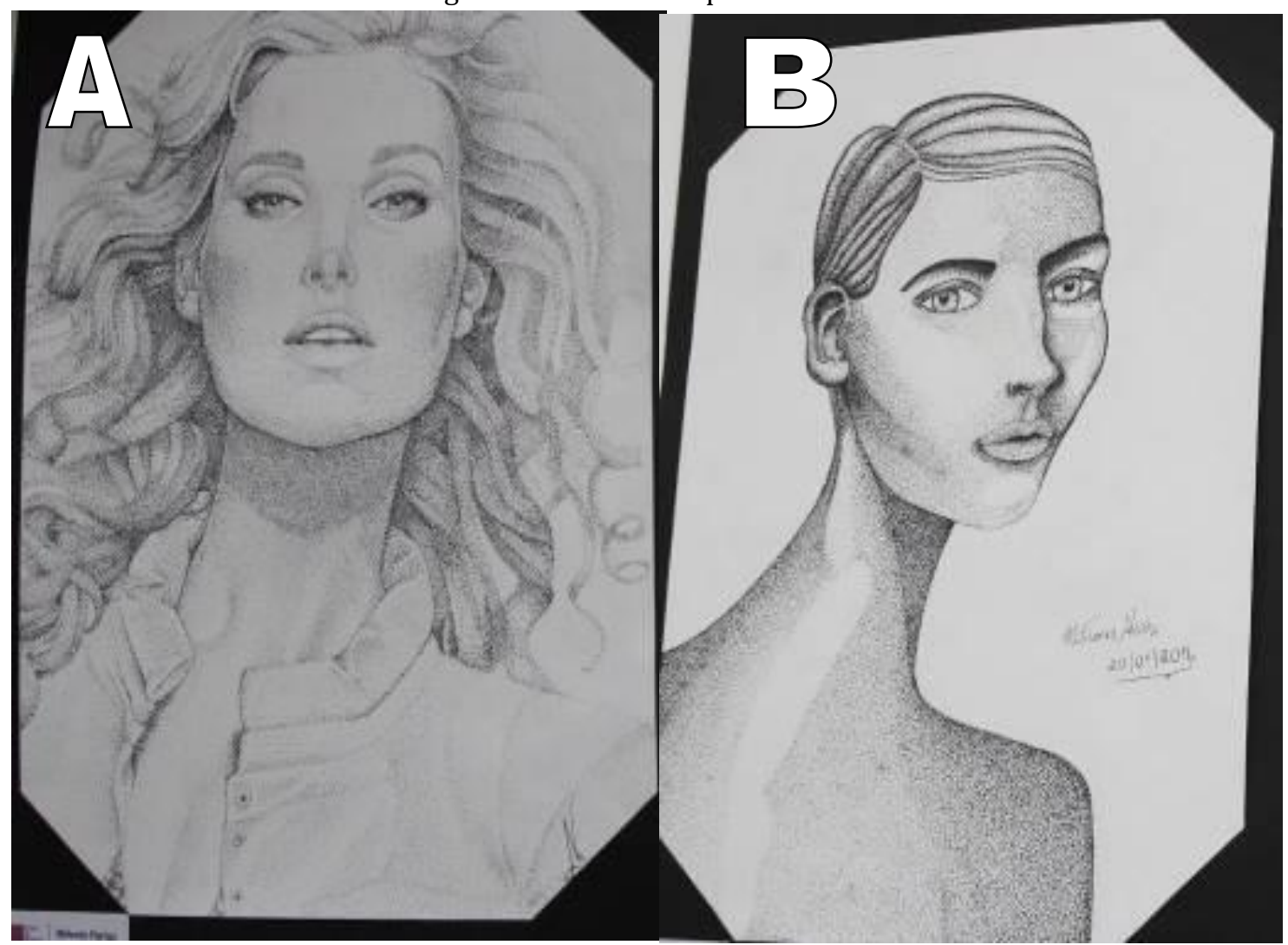

Fonte: IFPI campus Piripiri, 2016

0 desenho da figura $3 \mathrm{~A}$ apresentou maior domínio da técnica, pois o discente tanto domina a técnica de sombreamento como seu olhar sobre o desenho é mais sensível, mostrando mais realidade e sutileza nos traços e na composição dos pontos. Na imagem B trouxe o emprego do sombreado, porém o aluno ainda não tinha tanta prática com observação e sutileza no momento de passagem dos tons, ficando em alguns momentos listras no desenho, especialmente nos cabelos. 0 emprego do pontilhismo além de necessitar de um bom conhecimento de sombreado requer paciência ao realizar o desenho com apenas movimentos de pingos utilizando somente canetas nanquins.

Além do pontilhismo apresentado anteriormente, outras técnicas foram aplicadas no decorrer do curso. Na figura 4 mostra a atividade referente ao desenho realizado com lápis de cor. Esse método ajuda aos alunos de moda na visualização mais realista da roupa, pois mostra tanto o caimento, como texturas e volumes das vestimentas. 
Figura 4 - Desenho com lápis de cor.
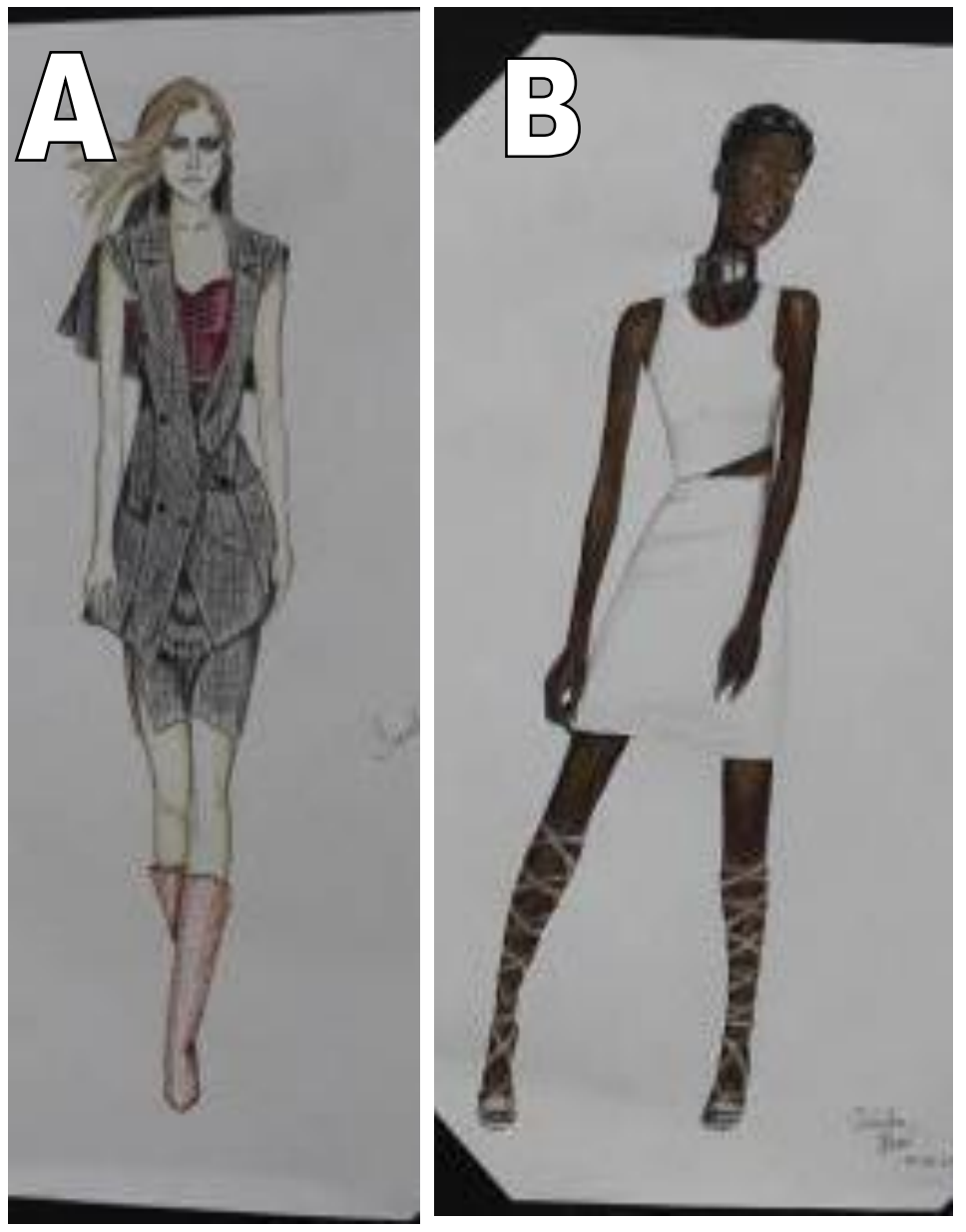

Fonte: IFPI campus Piripiri, 2016

Os desenhos feitos com lápis de cor foram o que apresentaram mais interesse por parte dos discentes, especialmente ao término de cada croqui. Na figura 4A o discente optou por desenhar uma pele mais clara, dando maior ênfase nas roupas com texturas e caimento no corpo ao ser representado no desenho, já o aluno da figura 4B trabalhou a pele negra, dando destaque ao desenho que fugia do desenho tradicional. Com isso, o discente valorizou a pele representando a cor intensa do marrom e preto ressaltando o branco do vestuário.

Na figura 5 exibem desenhos feitos com hidrocor compacta, com pontas finas e grossas, cujo objetivo foi definir o contraste de luzes e sombras sobre a pele e a vestimenta. Nesse trabalho, os alunos tiveram um pouco de dificuldade, para não deixar os desenhos marcados ou com sombreado estranho. 
Figura 5 - Desenho com hidrocor.

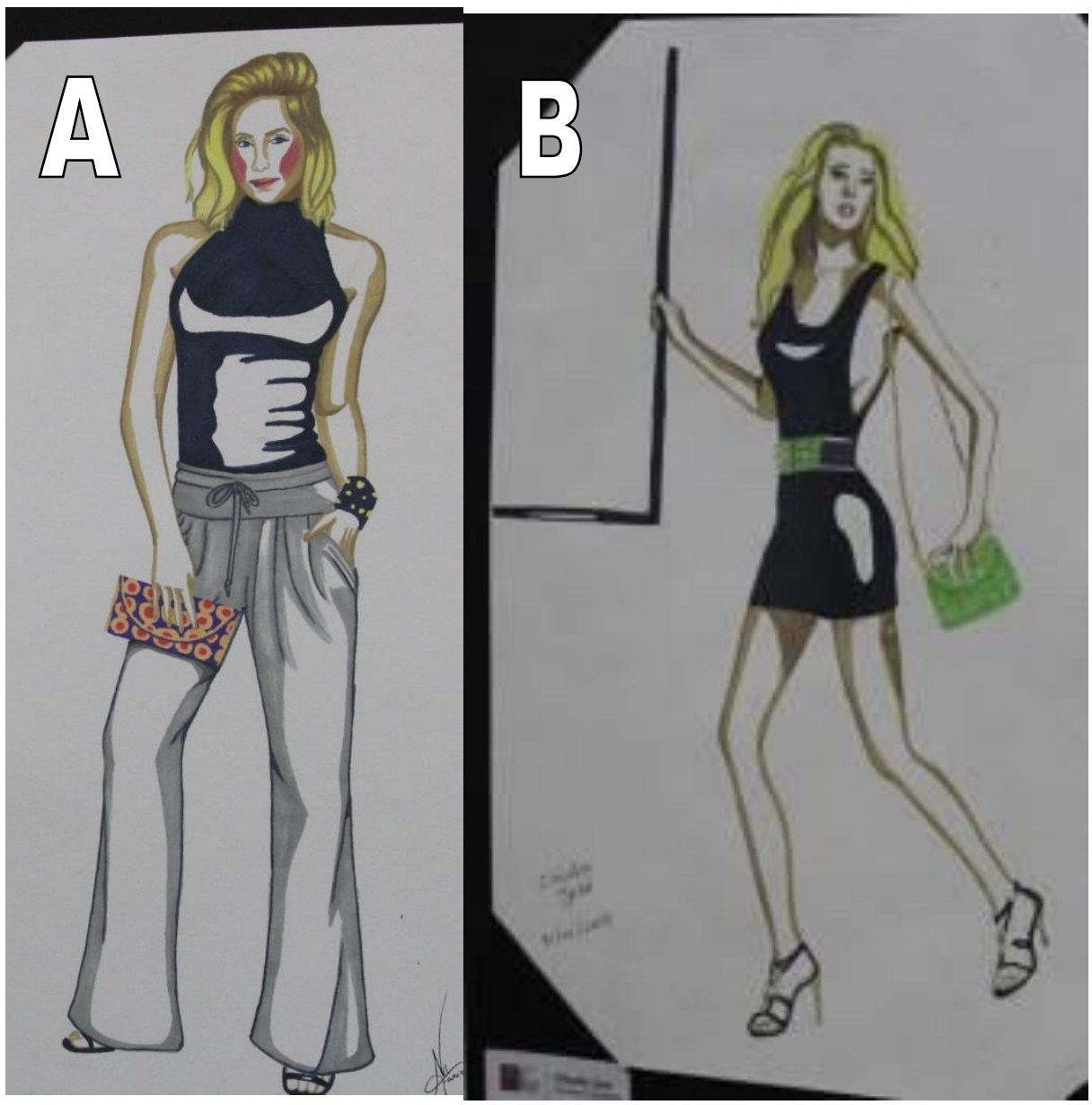

Fonte: IFPI campus Piripiri, 2017

Esse material também é usado para destacar efeitos nos tecidos como brilhos e matelassê. É uma das atividades mais simples e rápidas, segundo os discentes, porém qualquer traço errado ou indesejado pode estragar todo o exercício.

O último exercício ensinado foi uma técnica mista onde envolveu o lápis de cor, onde se coloriu o corpo da figura de moda e materiais diversos como: papeis, penas, arroz, etc., para compor o vestuário e os acessórios. Na figura 6 expõem o trabalho realizados por dois alunos na fase final do curso. 
Figura 6 - Desenho de moda técnica mista colagem e lápis de cor.
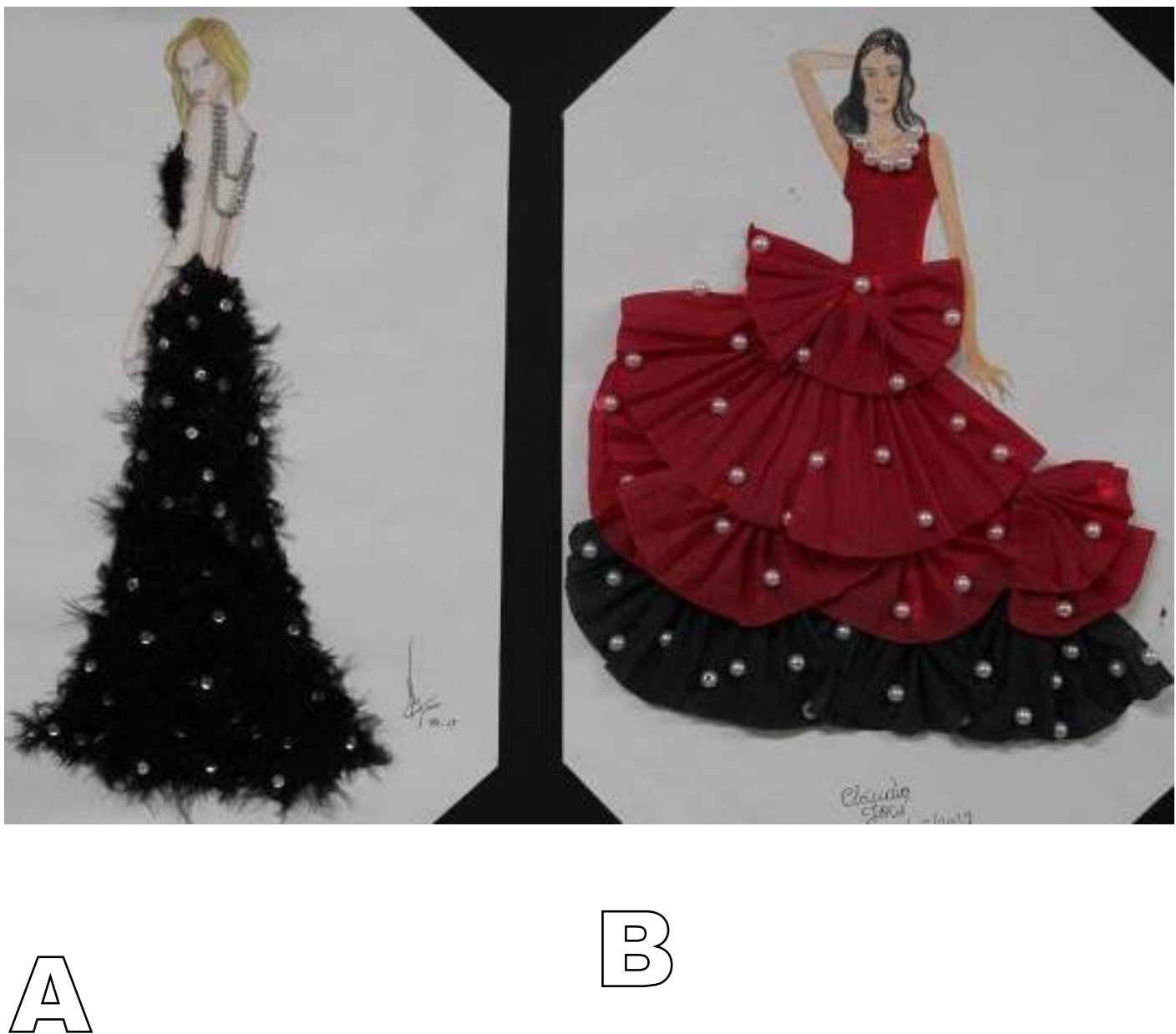

Fonte: IFPI campus Piripiri, 2017

Apesar de ser uma técnica relativamente fácil, alguns alunos sentiram dificuldades no momento de darem forma as peças de roupas, pois o trabalho de colagem sobre croqui nu, bloqueou no primeiro instante, a representação do caimento da peça em relação ao corpo, uma vez que alguns materiais trabalhados não representaram a forma tridimensional do tecido. Contudo, ao passar esse tempo, os discentes ficaram mais livres e familiarizados para a criação, aumentando, assim o poder de imaginação e memória visual.

Ao término do curso de extensão houve uma exposição no auditório do Instituto Federal do Piauí - Campus Piripiri, no evento Crie \& Pense moda, realizado pelos docentes e discentes dos cursos técnicos em vestuário e tecnólogo em design de moda. 0 evento aconteceu no dia 26 de maio de 
2017. A exposição dos desenhos também participou da primeira amostra de extensão, pesquisa e ensino da UESPI - Universidade Estadual do Piauí, acontecendo nos dias 29, 30 e 31 de maio. Para finalizar a exposição teve seu marco durante todo mês de setembro e início de outubro no museu de Perypery em Piripiri-PI, onde foi apreciado e admirado por visitantes do museu.

\section{CONSIDERAÇÕES FINAIS}

Após a realização das técnicas empregadas no curso de extensão foram alcançados todos os objetivos propostos em cada etapa do curso, não só ensinando as técnicas tradicionais, mas também exercitando a capacidade imaginativa, de abstração e memória visual dos discentes, além desses objetivos, pode-se observar que as vezes os discentes superaram-se, descobrindo novas técnicas e profissionalizando seus desenhos. Ainda que alguns tenham se sobressaído mais em determinadas etapas do que outros, todos demonstraram ter aprendido as técnicas estudadas.

Desse modo, acredita-se que o estudo do desenho e ilustração de moda é bastante instigante, necessitando de mais pesquisas envolvendo o assunto.

\section{REFERÊNCIAS BIBLIOGRÁFICAS}

LEITE, Adriana Sampaio; VELLOSO, Marta Delgado. Desenho técnico de roupa feminina. $2^{\mathrm{a}}$ ed. Rio de Janeiro, RJ: SENAC, 2007.

NUNES, M. L.; Teixeira, R. P.; FEIL, C.; PANIAGUA R., (2012). O Desenho da Figura Humana: uma perspectiva histórica. In: Wechsler S.M., Nakano T. C., (Org.). 0 desenho infantil: Forma de expressão cognitiva, criativa e emocional. São Paulo: Casa do Psicólogo, 2012, v. 1, p. 15-32.

RABELO, J. M.; MATOS, A. L. B. Laboratório de preenchimento tradicional. XXI Encontro de Extensão, Fortaleza, CE, 212. p. 2-17.

RIEGELMAN, Nancy. 9 cabeças: a guide to drawing fashion. California : Center College of Design, 2000

RIEGELMAN, Nancy. Colours for Modern Fashion - Drawing Fashion with Colored Markers. Ed. 9Heads Media, USA, 2006.

RODRIGUES, Ana Leonor M. Madeira. 0 que é Desenho. Lisboa Portugal: Quimera, 2003.

\section{AGRADECIMENTOS}


Obrigado ao Instituto Federal do Piauí pela oportunidade de fazer o curso de extensão em desenho e ilustração de moda. Agradeço a professora Cleidiane Carola e a técnica de laboratório Nylemar, pelo seu empenho na organização das exposições em três locais importantes na cidade de PiripiriPI. Ao meu bolsista Moisés agradeço com carinho, pelo auxílio nas aulas. Sou grata não só aos professores, colegas de profissão, mas também à direção, ao pessoal do administrativo, da limpeza e demais colaboradores da instituição, que além de proporcionar um ambiente saudável e muitos estímulos para participar de atividades acadêmicas, cooperaram com a realização do curso.

Por fim agradeço ao meu companheiro, colega de profissão Jean Herllington Araújo Monteiro, que incentivou e colaborou na apresentação do trabalho no Seminário do PPGDCI, realizado em 2017. 